\title{
Research into the Interaction between Investor Attention and Stock Prices
}

\author{
Yong-Jun ZHONG ${ }^{1, a}$, Lu LU ${ }^{1, b, *}$ \\ ${ }^{1}$ Mail box B037, International Business School, JINAN University, Zhuhai, China, 519000 \\ atzhongyj@jnu.edu.com, blulu19936@126.com \\ ${ }^{*}$ Corresponding author
}

Keywords: Investor attention, Overconfidence, Cointegration analysis.

\begin{abstract}
We use the number of posts of sample stocks in CSI 300 Index dated from 2009 to 2013 in the Oriental Fortune Forum to measure investor attention in Chinese stock markets and analyze the interaction between this attention and stock prices. We find that (1) stocks are held by optimistic investors in Chinese stock markets which lack the mechanism of short sales; (2) a fall in share price results less attention to stock markets on account of the departure of such investors. On the contrary, optimistic investors who are overconfident continually join in the stock markets and pay more attention to the markets as the stock prices go up, leading to a further rise in the stock prices.
\end{abstract}

\section{Introduction}

Hypothesis of rational man shows that rational investors have perfect ration and unlimited ability to process information. However, investors can only pay limited attention to the stock markets since there is a great deal of information presented every day. Kahneman(1973) proposed limited attention theory, holding the belief that attention is a limited scarce resource so investors must neglect other information while they pay attention to certain information [1]. This theory has aroused academic concern since it has important practical significance and research value.

Foreign scholars have been studying this phenomenon for quite a long time and have achieved significant results. Merton (1987) put forward the conception of investor recognition and pointed out that investor attention was related to stock prices and liquidity [2]. Della Vigna and Pollet(2009) found that stock price was less affected by news on Friday than on other weekdays (perhaps investors pay less attention to Friday news) [3]. Fang and Peress(2009) found a negative correlation between media coverage and the return of stock market [4].

Scholars divided their research objects into institutional investors and individual investors. Compared with individual investors, institutional investors have abundant money, professional knowledge and a great deal of information, taking the advantage of economies of scale. Bohl et al. (2006) proposed that institutional investors' attention will destabilize the stock price. However, with the help of Markov-switching-GARCH model, they found that the behaviour of institutional investors stabilized prices of Polish pension fund instead of destabilizing it [5]. In terms of individual investors, Aouadi et al.(2013)carried on research in the French stock market using the "Google insights for search" and found that trade volume was closely related to investor attention, which was also the determinant of the lack of liquidity and the volatility of stock market [6]. Stefan(2011) confirmed that the increase of investor attention would remarkably reduce the mispricing of American Depositary Receipts (ADRs) through the data on 536 stocks [7]. Van Nieuwerburgh and Veldkamp(2010) presented that limited investor attention would induce the lack of portfolio diversity [8]. Jun and Jiangfeng (2012) used the nearness to the Dow52-week high and the nearness to the Dow historical high to measure investors' reaction to news so as to predict the future tendency [9].

The research into investor attention in China mainly concentrates on empirical analysis. YU Qingjin and ZHANG Bing(2012)used panel regression and GARCH model to study the relationship between investor attention and fluctuation of the Growth Enterprises Market based on BAIDU INDEX [10]. 
Similarly, WANG Shu (2013) used the same index as proxy variable to study Chinese concept stocks and found that investor attention was not able to affect the return of market index but it would raise the liquidity of current concept stock index [11]. XUE Wenzhong(2012) et al found that investor attention led to heightened volatility [12]. YUAN Lingyun(2012) proposed that the information disclosure of strong individual stocks on the ranking list could reduce the influence to investors by extreme events[13].PENG Diefeng(2010) analysed the number of online news and found that focused stocks had high trade volume and stock turnover, bringing positive impact at first following the negative impact on its short run return[14].

As far as I am concerned, how the limited attention affects the behavior of investors and how the attention and stock prices interact with each other have become the focus of this passage as well as the crucial practice of behavioral finance. This passage studies the relationship between limited investor attention and the stock prices volatility based on the behavioral finance and micro-financial market theory. While previous academic studies use the extreme trade volume, excess earnings and media coverage to indirectly measure the investor attention, or use internet index to directly measure this attention, our paper directly measure the investor attention by the number of posts on Oriental Fortune Forum, which is the most famous forum for investors in China. In addtion, we confirm the relationship between investor attention and stock price volatility by VAR model and the theory of co-integration and the error-correction model, making the results more reliable and objective so as to provide advice to participants of stock markets.

The structure of this passage is organized as follows. Section 2 is theoretical framework. In Section 3 empirical study design is presented. Section 4 summarizes and concludes.

\section{The Theoretical Framework}

During the process of investment, investors will gather publicly published information such as media coverage and analysis reports to form their own opinions. In order to conclude this complicated behavior, we assume that investors obtain the noisy signal about the underlying dividend factor through the process of information and use these signals to form their own beliefs with the help of Byes Principle. We have:

$$
s_{i, t}=d_{i, t+1}+\varepsilon_{i, t}, \varepsilon_{i, t} \sim \mathrm{N}\left(0, \eta_{\mathrm{i}, \mathrm{t}}^{2}\right), \mathrm{i}=1, \cdots, \mathrm{n}
$$

where $s_{i, t}$ is the signal containing noises.

The more attention investors pay to, the more accurate the signal is. We introduce the idea of entropy in information theory according to Sims (2003). Basically, the entropy of a random variable measures its uncertainty, the signal of stock dividend $d_{i, t+1}$ contains gaussian distribution $N\left(\bar{d}_{i}, \sigma_{i}^{2}\right)$, so the entropy $H$ is decided by its variance $\sigma_{i}^{2}$ :

$$
H\left(d_{i, t+1}\right)=\frac{1}{2} \log \sigma_{i}^{2}+0.5 \log (2 \pi e)
$$

Where $\pi$ is Archimedes' constant and $e$ is Euler's constant. This expression is a direct expression where bigger variance indicates larger amount of uncertainty. After investors receive signal $s_{i, t}$, they update their beliefs based on Bayes Principle. Then investors' posterior beliefs are:

$$
d_{i, t+1} \mid s_{i, t} \sim \mathrm{N}\left(\hat{\mathrm{d}}_{\mathrm{i}, \mathrm{t}}, \hat{\omega}_{\mathrm{i}, \mathrm{t}}^{2}\right)
$$

where $\hat{d}_{i, t}, \hat{\omega}_{i, t}^{2}$ are conditional mean and conditional variance respectively. According to information theory, we define the amount of information $I\left(d_{i, t+1} ; s_{i, t}\right)$ in the signal $s_{i, t}$ over the period $d_{i, t+1}$ to be the reduction of entropy over that period:

$$
I\left(d_{i, t+1} ; s_{i, t}\right) \equiv H\left(d_{i, t+1}\right)-H\left(d_{i, t+1} \mid s_{i, t}\right)=\frac{1}{2} \log \left(\sigma_{i}^{2} / \hat{\omega}_{i, t}^{2}\right)
$$


Since signal $s_{i, t}$ is the output of the information processing, $I$ depends on the degree of attention to information. We assume that there is linear relation between these two variables:

$$
I\left(d_{i, t+1} ; s_{i, t}\right)=\frac{1}{2} \theta_{i} \kappa \lambda_{i, t}
$$

where $\kappa \lambda_{i, t}$ is the degree of investor attention input to the signal, $\theta_{i}>0$ is the parameters of information efficiency representing the efficiency of information processsing by investors. For a given value of $\theta_{i}$, as the investor allocates more attention to the signal,she process more information.

Consequently, we assume that investors may be overconfident in their ability to process information. The amount of information in signal $s_{i, t}$ lies on (6) instead of on (5):

$$
\hat{I}\left(d_{i, t+1} ; s_{i, t}\right)=\frac{1}{2} \phi \theta_{i} \kappa \lambda_{i, t}
$$

If $\phi>1$, investors are overconfident in their ability to process information so the amount of information is exaggerated; if $\phi=1$, this situation is unbiased. The above equation indicated that investors underestimate the uncertainty of signals, replacing $\eta_{i, t}^{2}$ with $\hat{\eta}_{i, t}^{2}$. Putting (5)(6) together and using the Bayes Principle, we have :

$$
1 / \hat{\omega}_{i, t}^{2}=1 / \sigma_{i}^{2}+1 / \hat{\eta}_{i, t}^{2}
$$

we obtain:

$$
\hat{\eta}_{i, t}^{2}=\sigma_{i}^{2} /\left(\mathrm{e}^{\phi \theta_{\mathrm{i}} \kappa \lambda_{\mathrm{i}, \mathrm{t}}}-1\right)
$$

the variance that investors perceive is less than the real variance,

$$
\eta_{i, t}^{2}=\sigma_{i}^{2} /\left(e^{\theta_{i} \kappa \lambda_{i, t}}-1\right)
$$

Given acquired signals and perceived amount of information, investors update their beliefs in $d_{i, t+1}$ based on Bayes Principle. The updated variance is

$$
\hat{\omega}_{i}^{2}=\sigma_{i}^{2} e^{-\phi \theta_{i} \kappa \lambda_{i, t}}
$$

The updated mean is:

$$
\hat{d}_{i, t}=\bar{d}_{i}+\left(1-e^{-\phi \theta_{i} \kappa \lambda_{i, t}}\right)\left(s_{i, t}-\bar{d}_{i}\right)
$$

where $\left(1-e^{-\phi \theta_{i} \kappa \lambda_{i, t}}\right)$ is the response to signals of $\hat{d}_{i, t} \cdot\left(1-e^{-\phi \theta_{i} \kappa \lambda_{i, t}}\right)$ increases as $\phi$ increases so overconfidence leads to the overreaction to signals.

Because Chinese stock markets lack the mechanism of short sales, pessimistic investors will stay out of the market (no longer concern about the stock market), stocks are held by optimistic investors, who exaggerate good news and ignore bad news. For example, Wu Xianglin (2003) found that there was overreaction when the stock prices reached their daily limits [15]. The common phenomenon is that the number of new accounts increases dramatically in bull markets while empty accounts appear in bear markets. Therefore, we can foresee that bull markets stimulate the investor attention. We can judge from (10) and (11) that under this circumstance, the dividends predicted by investors are far more than the actual ones. In addtion, less perceived variance than real one indicates overconfidence in investors' investment opinions, driving stock prices higher. As a result, we put forward the assumption for this paper: the rise in stock markets will arouse investor attention, which drives the stock prices higher. 


\section{The Empirical Analysis}

\section{Data sources and description}

The biggest challenge in the empirical analysis is that there is no direct measurement of investor attention. There are indirect proxy variables such as extreme returns, extreme stock turnover, the headlines and advertising expense. The assumption of such proxy variables is that the extreme return, extreme stock turnover, and mentioned stock names will grab investors' attention. Actually, there may be no relationship among extreme return, stock turnover and investor attention. Moreover, using the media coverage as proxy variables is not a valid method unless investors read the news. As we all know, the information explosion makes investors indifferent to the news. In this paper, we use the number of posts dated from 2009 to 2013 in the Oriental Fortune Forum, the most popular stock forum in China, to measure investor attention in Chinese stock markets. Undoubtedly, the number of posts will increase in the forum if investors pay attention to stock markets and vice versa. Consequently, the daily number of posts in the Oriental Fortune Forum is the direct proxy variable of investor attention. We collect the number of posts of sample stocks in CSI 300 Index dated from January 2009 to December 2013, summing them up on a monthly basis, and taking logarithm of them. We use that data as the measurement of investor attention. The other data for measurement is SSE Composite Index from CSMAR of the same scope.

Figure 1 demonstrates the relationship between investor attention and SSE Composite Index. As is shown in the figure, two variables move broadly together: the number of posts increases as the stock price rises and the number of posts decreases as the price falls, confirming our assumption. Compared to the monthly number of posts reaching 190997 when the index peaked at 3412 in July 2009, the corresponding number of posts was only 46101, which was nearly one fifth that of July 2009, when the index dropped to 2086 in October 2012.

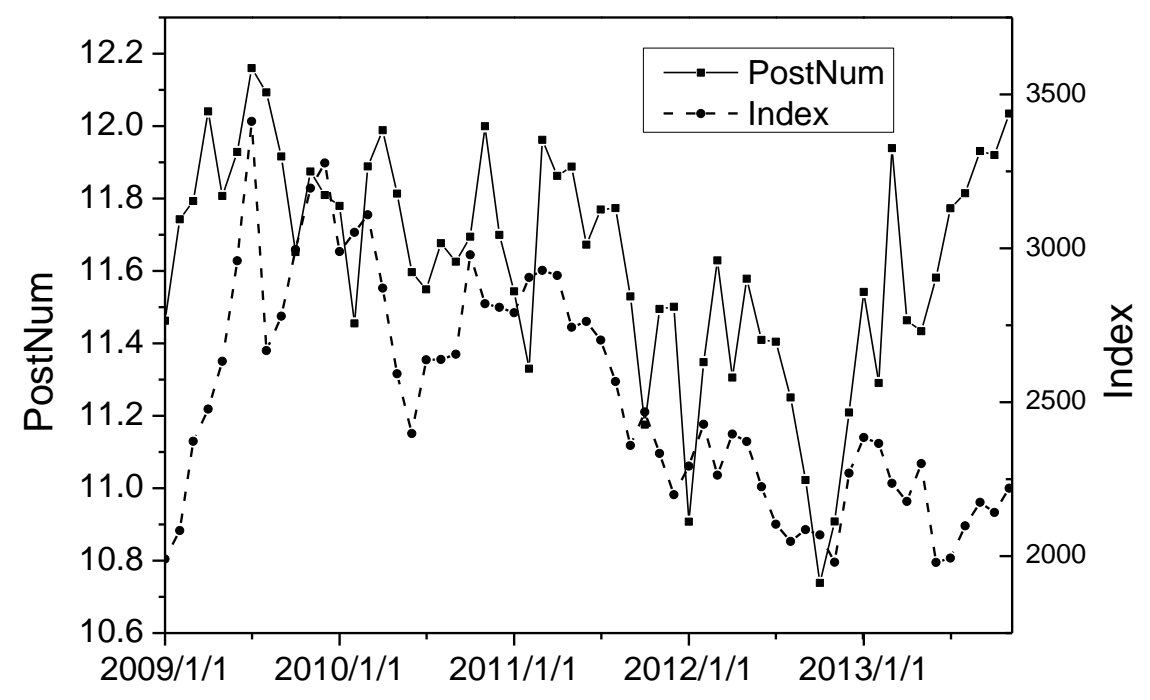

Figure 1.The relationship between investor attention and SSE Composite Index

\section{Empirical Analysis}

The result of ADF tests of SSE Composite Index and investor attention show that each of them has a unit root so we build the Error Correction $\operatorname{Model}(\mathrm{ECM})^{1}$. In order to examine whether the assumption is reasonable, we analyse the results of cointegration equation, Granger causality and the impulse response analysis.

\footnotetext{
(1) The result of ADF unit root is omitted because of space constraints.
} 
Cointegration analysis. Engle-Granger cointegration analysis method is used in this paper. To begin with, we perform a regression test on SSE Composite Index and investor attention to get the conintegration equation that reflects the long term relationship:

$$
\log (\text { Index })_{t}=5.24+0.222 \text { PostNum }_{t}+\varepsilon_{t}
$$

The ADF unit root testing shows that $\hat{\varepsilon}_{t}$ is stationary series, which indicates a long term relationship between SSE Composite Index and investor attention. The regression coefficient of the equation is postive and the $\mathrm{T}$ value is 4.082 . The result primary verifies that under the $1 \%$ significant level, stock prices will rise as the investor attention increases. Based on the cointegration equation model, we establish error correction model of one order lag identified by Akaike Information Criterion (AIC). The results of the model are presented in Table 1:

Table 1 The Error Correction Model

\begin{tabular}{c|c|c|c|c}
\hline Variable & Constant & $\begin{array}{l}\text { Deviation } \\
\hat{\varepsilon}_{t-1}\end{array}$ & $\Delta$ PostNum $_{t-}$ & $\Delta \operatorname{Ln}(\text { Index })_{t-:}$ \\
\hline$\Delta$ PostNum $_{t}$ & 0.0106 & $\begin{array}{l}-0.6080^{*} \\
(-2.6309)\end{array}$ & $\begin{array}{l}-0.3416^{*} \\
(-3.1267)\end{array}$ & $\begin{array}{l}1.7661 \\
(0.3808)\end{array}$ \\
& & & & -0.0439 \\
& & $0.1709 * *$ & -0.0224 & $(-0.3359)$ \\
\hline $\operatorname{Ln}($ Index $)$ & 0 & $(2.2214)$ & $(-0.6174)$ & \\
& & & & \\
\hline
\end{tabular}

Note:T values are in the brackets, $* * * * * * *$ are under the $10 \%, 5 \%, 1 \%$ significant level respectively.

Granger Causality test. To confirm the belief that the rise of stock prices can arouse investors' attention, we examine their causal relationship by Granger Causality test. According to Akaike Information Criterion, the optimal Lagged difference is second-order lag. Table 2 describes the result of Granger Causality test:

Table 2 Granger Causality Tests

\begin{tabular}{l|l|l}
\hline Null Hypothesis: & F value & P value \\
\hline POSTNUM does not Granger Cause LOG(INDEX) & 1.0801 & 0.3469 \\
\hline LOG(INDEX) does not Granger Cause POSTNUM & $8.4963^{* * *}$ & 0.0006 \\
\hline
\end{tabular}

As can be seen from the table, under the $1 \%$ significant level, stock price is the Granger Causality of investor attention. Our assumption is verified.

The result of impulse-response analysis. To further analyse the relationship between stock prices and investor attention, we we take a dynamic view with impulse-response analysis. Impulse-response analysis describes the impulse response of stock prices and investor attention. Figure 2 describes the dynamic mechanism of two variables during 12 periods. We can see from Figure 2(1) that one stock price standard deviation exerts postive impulse on investor attention in the first period and that positive impulse reaches its highest point $5 \%$ in the fourth period. This finding supports the earlier part of our assumption. We can see from Figure 2(2) that investor attention's impulse on stock prices increases dramatically at the beginning, reaching its highest point $0.5 \%$ in the fourth period. Comparing (1) with (2), we can conclude that the rise of stock price attracts investors and investor attention also drives the price higher. This phenomenon is more obvious at the beginning of the period. 


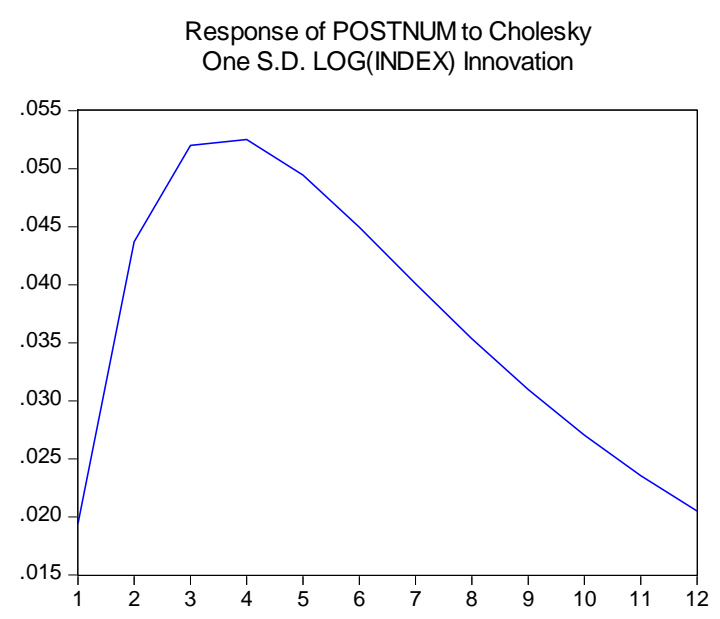

(1)

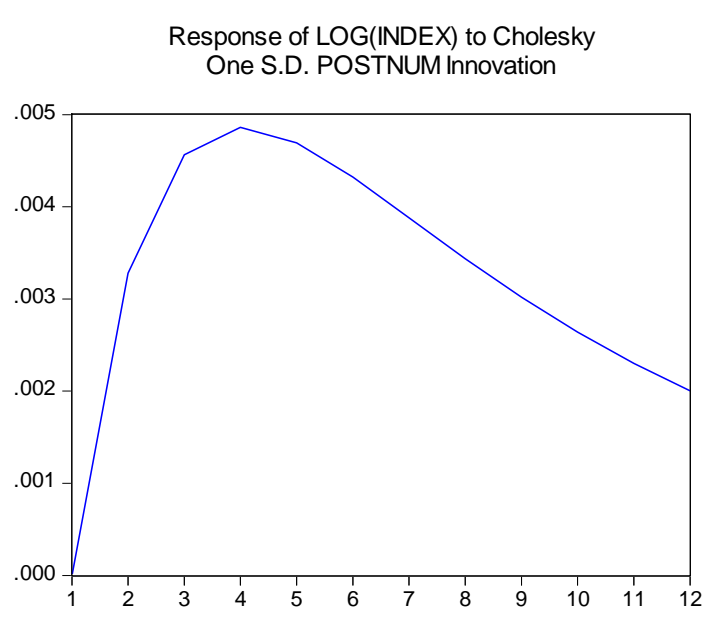

(2)

Figure 2. Impulse response functions of investor attention and stock price

\section{Conclusion}

Based on theoretical analysis, this paper studies the relationship between investor attention and stock price through co-integration, error correction model (ECM), the Granger causality and impulse-response analysis. The result shows that on the one hand, the rise of stock prices is the main factor to attract investor attention in Chinese stock markets which lacks the mechanism of short sales; on the other hand, overconfident behaviors by optimistic investors lead to a further increase of stock price. As a consequence, a positive feedback mechanism lies between investor attention and stock price.

\section{Acknowledgement}

This research was financially supported by the National Science Foundation (NO.71340016) and the Fundamental Research Funds for the Central Universities(NO.570290).

\section{References}

[1] Kahneman, D., Attention and effort, ed. P.S.I.E. Psychology. 1973: Prentice-Hall. x, 246.

[2] Merton R C. A simple model of capital market equilibrium with incomplete information [J]. The Journal of Finance, 1987, 42(3): 483-510.

[3] DellaVigna S, Pollet J M. Investor inattention and Friday earnings announcements [J]. The Journal of Finance, 2009, 64(2): 709-749.

[4] Fang L, Peress J. Media Coverage and the Cross - section of Stock Returns [J]. The Journal of Finance, 2009, 64(5): 2023-2052.

[5] Bohl, Martin T., Janusz Brzeszczyński, and Bernd Wilfling. "Institutional investors and stock returns volatility: Empirical evidence from a natural experiment."[J]. Journal of Financial Stability, 2009: 170-182.

[6] Aouadi A, Arouri M, Teulon F. Investor attention and stock market activity: Evidence from France [J]. Economic Modelling,2013, 35: 674-681.

[7] Stefan Eichler. Limited investor attention and the mispricing of American Depositary Receipts. Economics Letters, 2012: 490-492. 
[8] Van Nieuwerburgh S, Veldkamp L. Information acquisition and under-diversification [J]. The Review of Economic Studies, 2010, 77(2): 779-805.

[9] Jun Li, Jianfeng Yu. Investor attention, psychologicalanchors, and stock return predictability [J]. Journal of Financial Economics, 2012: 401-419.

[10] YU Qingjin, ZHANG Bing. Investor Attention and Stock Performance: An Empirical Study Using Baidu Index as the Proxy of Attention [J].Financial Research, 2012(08): 152-165.

[11] Wang Shu. Correlations between investors' attention and stock market index-Evidence from concept stocks. A Dissertation Submitted to Nanjing University For the Academic Degree of Master of Management Science and Engineering, 2013.

[12] Xue Wenzhong, He Zhongwei. Institutional Investors and Stock Market Volatility: Empirical Evidence from China A-share Market. Journal of Dalian Maritime University, 2012(03): 14-18.

[13] Yuan Lingyun. An Investigation of Abnormal volatility caused by limited attention A Dissertation Submitted to Southwestern University of Finance and Economics University For the Academic Degree of Master, 2012.

[14] RAO Yu-lei, PENG Die-feng, CHENG Da-chao. Does media attention cause abnormal return? Evidence from China's stock market[J] Systems Engineering一Theory \& Practice, 2010(2): 287 - 297.

[15] Wu Linxiang, Xu Longbing, Wang Xinping. Do Price Limits When Prices Close Investor Overreaction At Price Limits? [J]. Economic Research, 2003(10): 59-65. 